\title{
BMJ Open Decision-making dilemmas of paediatricians: a qualitative study in Japan
}

\author{
Momoko Sasazuki, ${ }^{\oplus 1,2}$ Yasunari Sakai, ${ }^{\oplus 1}$ Ryutaro Kira, ${ }^{3}$ Naoko Toda, ${ }^{1}$ \\ Yuko Ichimiya, ${ }^{1}$ Satoshi Akamine, ${ }^{1}$ Michiko Torio, ${ }^{1}$ Yoshito Ishizaki, ${ }^{1}$ \\ Masafumi Sanefuji, ${ }^{1}$ Miho Narama, ${ }^{4}$ Koichiro Itai, ${ }^{5}$ Toshiro Hara, ${ }^{6}$ \\ Hidetoshi Takada, ${ }^{7}$ Yoshiyuki Kizawa, ${ }^{8}$ Shouichi Ohga ${ }^{1}$
}

To cite: Sasazuki M, Sakai Y, Kira $\mathrm{R}$, et al. Decisionmaking dilemmas of paediatricians: a qualitative study in Japan. BMJ Open 2019;9:e026579. doi:10.1136/ bmjopen-2018-026579

- Prepublication history and additional material for this paper are available online. To view these files, please visit the journal online (http://dx.doi. org/10.1136/bmjopen-2018026579).

Received 11 September 2018 Revised 21 July 2019 Accepted 23 July 2019
Check for updates

(C) Author(s) (or their employer(s)) 2019. Re-use permitted under CC BY-NC. No commercial re-use. See rights and permissions. Published by BMJ.

For numbered affiliations see end of article.

Correspondence to Dr Yasunari Sakai; ysakai22q13@gmail.com

\section{ABSTRACT}

Objective To delineate the critical decision-making processes that paediatricians apply when treating children with life-threatening conditions and the psychosocial experience of paediatricians involved in such care. Design We conducted semistructured, individual faceto-face interviews for each participant from 2014 to 2015. The content of each interview was subjected to a comprehensive qualitative analysis. The categories of dilemma were extracted from a second-round content analysis.

Participants Participants were board-certified paediatricians with sufficient experience in making decisions in relation to children with severe illnesses or disabilities. We repeated purposive sampling and analyses until we reached saturation of the category data.

Results We performed interviews with 15 paediatricians. They each reported both unique and overlapping categories of dilemmas that they encountered when making critical decisions. The dilemmas included five types of causal elements: (1) paediatricians' convictions;

(2) the quest for the best interests of patients; (3) the quest for medically appropriate plans; (4) confronting parents and families and (5) socioenvironmental issues. Dilemmas occurred and developed as conflicting interactions among these five elements. We further categorised these five elements into three principal domains: the decision-maker (decider); consensus making among families, colleagues and society (process) and the consequential output of the decision (consequence).

Conclusions This is the first qualitative study to demonstrate the framework of paediatricians' decisionmaking processes and the complex structures of dilemmas they face. Our data indicate the necessity of establishing and implementing an effective support system for paediatricians, such as structured professional education and arguments for creating social consensus that assist them to reach the best plan for the management of severely ill children.

\section{INTRODUCTION}

Paediatricians are expected to make ethically appropriate decisions for children facing life-threatening conditions. Improvements in life-supporting treatment for severely ill

\section{Strengths and limitations of this study}

- This is the first qualitative study to clarify what paediatricians experience when they make critical decisions for severely ill children.

- The content analysis illustrates the structure of dilemmas that paediatricians struggle with when they seek the best management plans.

- The effect of Japanese culture on the decision-making process requires further evaluation.

children has led to improved survival rates, but it has also led to moral dilemmas for paediatricians who need to decide whether the use of such treatment is beneficial for their patients. ${ }^{1}$ Currently, there is no consensus among paediatricians about maintaining their ethical responsibilities with respect to patients. $^{2}$ Thus, in their decision-making, paediatricians and professionals involved in child care today need to understand the unspoken words of children and pay proper attention to the dignity and the comfort of the patients and their families.

Within their relatively limited experience, physicians are often under tremendous strain when they have to reach to the best plan for their patients through critical decision-making. This is particularly the case with paediatricians-in comparison to specialists in adult and geriatric medicine, they are less frequently involved in the treatment of patients suffering from life-threatening conditions. ${ }^{3}$ However, the current guidelines only discuss general principles of ethical thinking and do not necessarily provide an ethical standard for practice in individual cases. ${ }^{4}$ Consequently, paediatricians make empirical decisions about the direction of therapy, which largely depend on what they consider to be essential for their patients' well-being. ${ }^{5-10}$ Experts in paediatric palliative 
medicine also have difficulty due to a lack of evidencebased research in this area. ${ }^{11} 12$ For these reasons, paediatricians await a practically useful system that can support them in their decisions and offer patients appropriate treatment options.

In the present study, we investigated how paediatricians underwent critical decision-making for children with life-threatening illnesses or severe disabilities.

\section{METHODS}

\section{Participants}

The inclusion criteria were paediatricians who had been engaged for more than 5 years in decision-making for children with life-threatening illnesses or severe disabilities. For purposive sampling, ${ }^{13-15}$ we carefully planned how to maintain diversity in the participants' clinical backgrounds and in the regions in which their workplaces were located. We sought board-certified paediatricians who worked with children and were heads of their section at national university hospitals (interviews 1,3 and 5). After each interview, we asked participants whether or not they could introduce us to more potential participants. We therefore used the snowball sampling technique for subsequent recruitment (interviews $1>2>15) .{ }^{16}$ In addition to this approach, we searched for eligible participants by asking directors of departments at tertiary-level children's hospitals in Tokyo and Fukuoka. We interviewed the three paediatricians who were introduced to us by these directors (interviews 4, 11 and 12). To recruit other participants, we directly asked specialists in related fields (critical care medicine, neonatology, oncology and neurology) whether or not they would be willing to participate in this study (interviews $6,7,8,9$, 10,13 and 14). We obtained contact information from all participants, including their email address, after receiving their permission.

After each interview, we continued to seek optimal paediatricians according to the prior analysis throughout the study period. The interviewer (MSS) works as a paediatrician and serves as an administrator of palliative care in the same department. She continued to interact with other paediatricians during the study period. Considering the possibility that preinterview and postinterview communication with participants may have affected the results of our interviews, we decisively excluded participants who were employed in the same workplace during the study period. Three of the 15 participants used to work with children in the same department as the interviewer (MSS); however, none of them worked there during the same period. No candidates declined to participate in our study. We coupled the data analysis with purposive sampling until theoretical saturation was reached. As a second round of purposive sampling, additional participants ( $>10 \%$ the number of subjects at the previous stage) were recruited to verify that theoretical saturation had been reached (table 1$)$.

\begin{tabular}{|c|c|c|}
\hline Demographics & Variable & Number \\
\hline \multirow[t]{2}{*}{ Sex } & Male & $12+2^{*}$ \\
\hline & Female & 1 \\
\hline \multirow[t]{5}{*}{ Age } & $30-34$ & 1 \\
\hline & $35-39$ & 6 \\
\hline & $40-44$ & $5+1$ \\
\hline & $45-49$ & $0+1$ \\
\hline & $50-54$ & 1 \\
\hline \multirow[t]{5}{*}{ Subspecialty } & $\begin{array}{l}\text { Paediatric intensive } \\
\text { care }\end{array}$ & 3 \\
\hline & Paediatric cardiology & $1+1$ \\
\hline & Neonatology & 3 \\
\hline & Paediatric neurology & 4 \\
\hline & Paediatric oncology & $2+1$ \\
\hline \multirow[t]{4}{*}{ Geographic region } & Hokuriku & 1 \\
\hline & Kanto & $3+1$ \\
\hline & Kansai & 2 \\
\hline & Kyushu & $7+1$ \\
\hline
\end{tabular}

${ }^{*}$ The number after the plus (+) indicates the number of participants who were recruited for the validation phase.

\section{Interviews}

A specific guide for the interviewer was prepared in advance (online supplementary table 1). All interviews in this study were conducted in compliance with this regimen. ${ }^{17}$ Individual face-to-face interviews were conducted from July 2014 to December 2015 (see online supplementary digital information).

The indexes of the interviews (nos. 1-13) represent the chronological order of the interviews that we performed during the study period. We first interviewed paediatricians who specialised in critical care medicine, as we believed that they had substantial experience with the topic at hand. We therefore conducted the first three interviews in the order of no. 1 to 3. These three participants talked about their experience dealing with distress when making critical decisions. They felt such distress because their decisions had direct effects on the survival of their patients.

On analysing the data from the first three interviews, we concluded that we should test whether or not the decision-making process differs between cases of acute and chronic disorders. We therefore next contacted physicians who worked with children who had chronic diseases (nos. 4-6). These data revealed how paediatricians attempt to find external references for evaluating the quality of life and justifying their own decisions. In one (no. 4) of these three interviews, the participant's feelings were associated with confusion due to a lack of experience (4/q87, 4/ $\mathrm{q} 90)$. This finding led us to seek out paediatricians who had similar or more experiences than no. 4 (no. 7). 
These six interviews prompted us to locate paediatric oncologists, as these doctors had more chances than other paediatricians to interact with severely ill children themselves (nos. 8 and 9). These two paediatricians commonly expressed their confusion concerning their relationships with the patients, which differed markedly from their relationships with the patients' parents. Furthermore, one (no. 8) reported difficulty in arranging homecare physicians and nursing services for severely sick children. We therefore next searched for paediatricians who had a strong background in community-based medicine and practice (no. 10).

Finally, we attempted to contact physicians who were the heads of their department. We planned to recruit such paediatricians because we expected them to have experience with making difficult decisions and subsequently overcoming those hurdles (nos. 11-13). We repeatedly performed sampling, processing and analyses of verbatim data until we finished these 13 interviews. We then concluded that we had reached data saturation.

To ensure that the quality of the sessions remained consistent, MSS interviewed all participants. MSS is a board-certified paediatrician and has been a core administrator of the paediatric palliative care team at Kyushu University Hospital. She has been engaged in medical care for children with life-threatening conditions for more than 20 years as both a child neurologist and a specialist in palliative care. While she paid a higher attention to the topic of the decision-making process that participants described in the interviews, she was aware of the potential impact of reflexivity and sought to avoid misleading, judging or implying a forceful message during the interviews and at any steps of the data analysis. ${ }^{18} 19$ YS, RK, NT, Y Ichimiya, MT and SA are also board-certified paediatricians with sufficient experience in caring for children with life-threatening conditions. The other researchers who analysed the data included YK, a palliative care physician; $\mathrm{MN}$, a certified nurse specialist in child health nursing and KI, a medical ethicist. All of these researchers have extensive experience in this area and work in university hospitals for children with severe illnesses.

\section{DATA ANALYSES}

We first transcribed the recorded interview contents verbatim. MSS and another researcher (YS or RK) then coded the minimised passages with the grounded theory approach. ${ }^{20}$ The grounded theory approach is an established method that enables researchers to extract a new theory through the repeated process of making an inquiry, collecting data from different participants, comparing them and re-examining the questions for further data mining. ${ }^{21}$ This method asks researchers to follow stringent steps in the data analysis, which involves line-by-line coding and the development of categories. In brief, we first obtained hundreds of Japanese words and passages per interview after dissecting the spoken words of participants. According to the principle of the grounded theory approach, we then extracted categories and explored whether or not the meanings of each category might be connected under a superordinate concept.

To ensure the coherence of the verbal data, the two coders held repeated discussions when generating new codes. The coded data were inductively generalised to subcategories and further conceptualised to larger main categories (see online supplementary table 2). To avoid misinterpretation and arbitrariness, we repeated these processes with MSS paired with another coder. We summarised the relationships among the extracted categories in a correlation diagram (see online supplementary figure 1).

For triangulation, ${ }^{22} 11$ more members joined the team for the data analysis and interpretation. These contributors also analysed the verbatim data using the grounded theory approach and then performed a content analysis (see the next section) to closely examine certain categories. Among them, YK, MN and KI were experienced qualitative researchers. ${ }^{23}$ The eight neurologists and neuroendocrinologists (YS, RK, NT, MT, SA, MS, Y Ichimiya and $\mathrm{Y}$ Ishizaki) had research backgrounds in clinical statistics (all eight), genetics (YS, RK, MT, SA), neuroimaging (MT and MS) and unsupervised bioinformatics data analyses (YS, RK and SA).

The Microsoft Office software suite (Microsoft Excel) was used to perform all of the analytical procedures involved in the organisation of scripts, the encoding of data and the production of the graphic output.

\section{Validation of analyses}

To further analyse the dilemma categories, MSS conducted a second-round analysis of each interview with one of the following researchers: RK, YS, SA or MT. In this round, subcategories that were connected with the paediatricians' dilemmas were extensively scanned according to a standard inductive content analysis method ${ }^{24}$ (see online supplementary table 3 ). To verify the quality of this study, the transcripts were independently analysed by a specialist in the field of palliative care (YK). In this way, we were able to confirm the consistency of more than $70 \%$ of the subcategories and ensure the validity. ${ }^{24}$ Finally, to reconfirm the subtle definition of the codes and subcategory groups, MSS and YK conducted repeated discussions. These validation procedures confirmed that the extracted categories were saturated. All study procedures conformed with the consolidated criteria for reporting qualitative research. ${ }^{17}$

\section{Patient and public involvement}

No patients were involved in this study. The 15 participants were all $\mathrm{MD}$, and no identifiable patient information were disclosed in their interviews. We will thank them both personally and publicly for their cooperation when we report the data in the academic society. The main conclusion of this study directly indicates the development of the research question as well as the outcome measures in future paediatrics. 


\section{RESULTS}

\section{Diverse subspecialty and variable processes for decision- making}

We repeated the purposive sampling and data analysis cycles until the concepts reached theoretical saturation. After the 13th interview and analysis, we found that the theories extracted from data had reached saturation. The participants were from different parts of Japan and from five different specialist fields (table 1 ).

We found that all 13 paediatricians had experienced dilemmas when making critical decisions about treatment plans for children facing life-threatening conditions. Accordingly, we extracted text passages that reflected the participants' dilemmas in making critical decisions, and we inductively characterised that content. To verify that we obtained theoretical saturation, we recruited two additional participants for interview (table 1). By repeating our analysis with these two interviews, we confirmed that all the subcategories were classified into one of the categories that had been extracted from the 13 interviews.

\section{Five essential elements in paediatrician dilemma}

The content of conflicting thoughts varied with specific events that the participants had experienced; thus, the nature and origin of their dilemmas could hardly be classified into a single category. Nonetheless, we found that their dilemmas stemmed from one or a combination of five categories: (1) paediatricians' convictions; 2) the quest for the best interests of patients; (3) the quest for medically appropriate plans; (4) confronting parents and families and (5) socioenvironmental issues (table 2). The details of their nature are described in the following sections.

\section{Paediatricians' convictions}

The contents in this category showed evidence that the participants referred to internal standards of virtue for what they considered to be right, but not to external norms. All of the participants repeatedly stated their sense of mission as a physician caring for children with severe illnesses or disabilities and expressed how they wanted to fulfil that mission. They also articulated their values and commitments as professionals toward making acceptable decisions in terms of ethics, patient-physician relationships, and in compliance with society. Among the 17 subcategories in this category, 9 were associated with their philosophy of righteousness (Category I.1-9, tables 2 and 3). Participants wished to do the right things as physicians (Category I.5). This subcategory was derived from 9 of the 15 interviews.

\section{Quest for the best interests of patients}

The words in this category reflected what participants asked themselves when they were considering the best interests of their patients. Three subcategories (category II.1-3, table 2) belonged to this category. These subcategories represented how paediatricians tried to assess the children's best interests by carefully observing their comfort, dignity and quality of life. Participants expressed anxiety when they had difficulty identifying the child's best interests (5/q196, table 3). Their distress seemed to affect their decisions regarding life-sustaining treatment. Thus, these data suggested that each paediatrician's quest for the best interests of the patient was an essential element that caused dilemmas during and after decision-making.

\section{Quest for medically appropriate plans}

The words in this category included physicians' distress concerning the planning of medication and treatments. Through the 15 interviews, we observed that the participants experienced dilemmas when seeking 'medically appropriate plans' (category III.1-8, table 2). First, this type of dilemma was likely to emerge from an unconscious quest to be right. Second, participants sought treatments that were proven to be scientifically effective or appropriate in similar conditions to those of their patients. When they felt doubt about justifying their plans, they tried to overcome that by maximising their efforts to prolong their patients' lives (3/q17 and 9/q99, table 3).

\section{Confronting parents and families}

The participants also showed unstable conditions in their relationships with parents and families. This category contained three subcategories of dilemma (category IV.1-3, table 2). Participants experienced dilemmas when parents seemed unrealistic or overly optimistic about their child's condition and also when they noticed that the possibility of a family caring for a severely ill child at home was limited (5/q58 and 9/q54, table 3 ).

\section{Socioenvironmental factors}

The participants experienced difficulty that was caused by a lack of social consensus. The contents in this category showed that the participants craved the availability of consensus justifying their decision-making process. Their dilemmas in this category appeared when they struggled to reach agreement with the family, medical staff or society (11/q196, online supplementary information). We observed such dilemmas in 11 of the 15 interviews across different subspecialties and backgrounds.

Five subcategories belonged to this category (category V.1-5, table 2). Dilemmas in this category were associated with the social, human and economic resources of a family as well as equipment or therapeutic devices for supporting sick children at home. Deficiencies in such areas would mean that a family could not care for a child with a serious disease at home. We therefore considered families incapable of providing home care for a child to be a cause of dilemma (10/q75, table 3$)$. Dilemmas in this category also indicated that support systems, social consensus and written guidelines for decision-making were unavailable $(8 / \mathrm{q} 59$, table 3$)$.

\section{Interactions of the five elements}

Finally, we found some struggling episodes that were difficult to classify into a one of the five abovementioned categories. An extended content analysis revealed that these 
Table 2 The five main categories of paediatricians' dilemmas and their subcategories

\section{The quest for the best} interests of patients

III. The quest for medical
appropriate plans

IV. Confronting parents and families

\begin{tabular}{lll}
$\begin{array}{l}\text { V. Socioenvironmental } \\
\text { issues }\end{array}$ & $\begin{array}{l}\text { 1. Limited use of current guidelines for making ethically appropriate decisions. } \\
\text { 2. Lack of consensus regarding use of medical resources. }\end{array}$ \\
3. Insufficient local resources. & $\begin{array}{l}\text { 4. Regional differences among resources. } \\
\text { 5. Recognising the fact that severe neonatal asphyxia, which leads to severe mental } \\
\text { retardation and disability, will not be diminished. }\end{array}$ \\
\hline
\end{tabular}

included dilemmas that fell into multiple categories, as well as conflicting or synergistic interactions among different categories of dilemmas. Thus, we focused on the time course and context-forming process of each dilemma. This allowed us to investigate the interactive relationships among the five elements. Extensive content analyses showed that 64 of the 101 dilemmas identified in this study arose with combinations of conflicts among the five categories. We found that one particular type of dilemma developed through a conflict among different

\section{Subcategory}

1. Lack of confidence.

2. Bearing heavy responsibility for the child's life.

3. Fear of the child dying.

4. Hesitation about discussing the inevitable death of the child with the child's parents.

5. Wanting to be correct as a doctor.

6. Not wanting to be hurt.

7. Not wanting to be wrong or blamed.

8. Recognising the limitation of an individual physician's ability to assure the child's happiness.

9. Need for humanity as a paediatrician in being responsible for a child's life.

10. Being unable to accept the idea of withholding life-sustaining treatment for a child.

11. Uncertainty regarding the physician's role in decision making.

12. Recognition of self-righteousness in decision-making.

13. Contradictions in withdrawing treatment against one's own intentions.

14. Difficulty in talking about the inevitable death or severe prognosis of a child while recognising its importance.

15. Sense of responsibility in making the final decision for the child as the attending physician.

16. Lack of education and knowledge about treatment, strategy of decision-making and medical resources for a child with a life-threatening condition.

17. Lack of experience in treating a child with a life-threatening condition.

1. Wanting to act in the child's best interests.

2. Difficulty in determining the child's best interests.

3. Difficulty in imaging the pain of a child with neuromuscular disease.

1. Uncertainty of the prognosis.

2. Difficulty in evaluating the validity of treatment.

3. Lack of data to support making appropriate plans.

4. Criticism concerning unusual plans and non-standard care.

5. Lack of unified correct answers.

6. Reluctance in refraining from offering a feasible plan because of a child's severe disability.

7. Importance of accurate evaluation in recognising the inevitable death and limited time remaining to a child with a life-threatening condition.

8. Difficulty in making the right decision in a limited time frame.

2. Difficulty in dealing with parents who have unconventional thoughts.

3. Knowing the difference among families regarding levels of affection and availability of people to look after their child.

Ethical (E) or

compor

$P>E$

$P>E$

$P>E$

$P>E$

$E>P$

$E>P$

$E>P$

$P>E$

$E>P$

$E>P$

$\mathrm{P}>\mathrm{E}$

$\mathrm{P}>\mathrm{E}$

$P>E$

$P>E$

$E>P$

$E>P$

$P>E$

$P>E$

$P>E$

$P>E$

$P>E$

$P>E$

$P>E$

$\mathrm{P}>\mathrm{E}$

$P>E$

$P>E$

$E>P$

\section{$E>P$}

$P>E$ retardation and disability, will not be diminished. 


\begin{tabular}{|c|c|c|c|}
\hline $\begin{array}{l}\text { Main } \\
\text { category }\end{array}$ & Subcategory & $\begin{array}{l}\text { Interview/ } \\
\text { quote no. }\end{array}$ & Quote \\
\hline \multirow{2}{*}{ I } & 5 & $\begin{array}{l}14 / q 151- \\
q 154\end{array}$ & $\begin{array}{l}\text { 'Doctors have to be right. I have to be right. I always make efforts to justify my } \\
\text { action medically, scientifically, mentally, and emotionally.' }\end{array}$ \\
\hline & 16 & 11/q251 & $\begin{array}{l}\text { 'We have no experience of choosing extubation, and we don't know how we } \\
\text { can rationalize that option. There is a need for structuralized education.' }\end{array}$ \\
\hline II & 3 & 5/q196 & $\begin{array}{l}\text { 'I don't have a clear answer to the question of whether children with spinal } \\
\text { muscular atrophy type } 1 \text { are unhappy or suffering: since birth, they have been } \\
\text { unable to move by themselves.' }\end{array}$ \\
\hline & 8 & 9/q99 & $\begin{array}{l}\text { 'Even if it might not turn out how we expected, it is better to do what is } \\
\text { medically appropriate and feasible. That is particularly true when you can't tell } \\
\text { what the best is for the child at the time of the decision.' }\end{array}$ \\
\hline \multirow[t]{2}{*}{ IV } & 2 & $5 / q 58$ & $\begin{array}{l}\text { 'After we provided parents with objective data showing the severity of their } \\
\text { child's condition, they didn't accept our viewpoint. Instead, they just hoped } \\
\text { for a miracle. It was difficult to discuss with the parents what we could offer as } \\
\text { alternative options.' }\end{array}$ \\
\hline & 3 & 9/q54 & $\begin{array}{l}\text { 'It depends on the family's personal capacity or intention to take their child } \\
\text { home or not.' }\end{array}$ \\
\hline
\end{tabular}

*2/q28 represents the quote (q) number 28 in interview 2.

categories of dilemma. The newly extracted 10 categories (categories $\mathrm{VI}-\mathrm{XV}$, online supplementary table 4) indicated that the five elements were connected to one another via cause-and-effect relationship (figure 1). A quote in category VII.2 is an example of such interacting dilemmas (table 4).

The participant indicated that their dilemma emerged when trying to bear the parents' pain and burden combined with the maximal efforts exerted for the child as a professional paediatrician. We observed that this type of dilemma contained causative elements of categories I (paediatricians' convictions) and IV (confronting parents and families); their conflicting interaction also contributed to the development of dilemmas in a complex manner.

Some dilemmas developed when participants tried to achieve consensus with other staff over treatment plans (4/q118, table 4; category IX.8, online supplementary table 4). This dilemma developed from conflict between categories I (paediatricians' convictions) and V (socioenvironmental factors).

\section{DISCUSSION}

Based on recorded data from 15 semistructured interviews of board-certified paediatricians, we characterised their psychosocial experience in decision-making. The deep qualitative analysis revealed that the paediatricians suffered from various types of dilemmas that varied according to the case and the physician's sense of values or experiences. On analysing the components of the dilemmas, we identified five major elements. Our data indicate that each type of dilemma developed over time and that there were two or more conflicting interactions among the five elements.

In addition to extracting the causative elements that resided in each dilemma, we were also trying to understand the decision-making process of each participant. 


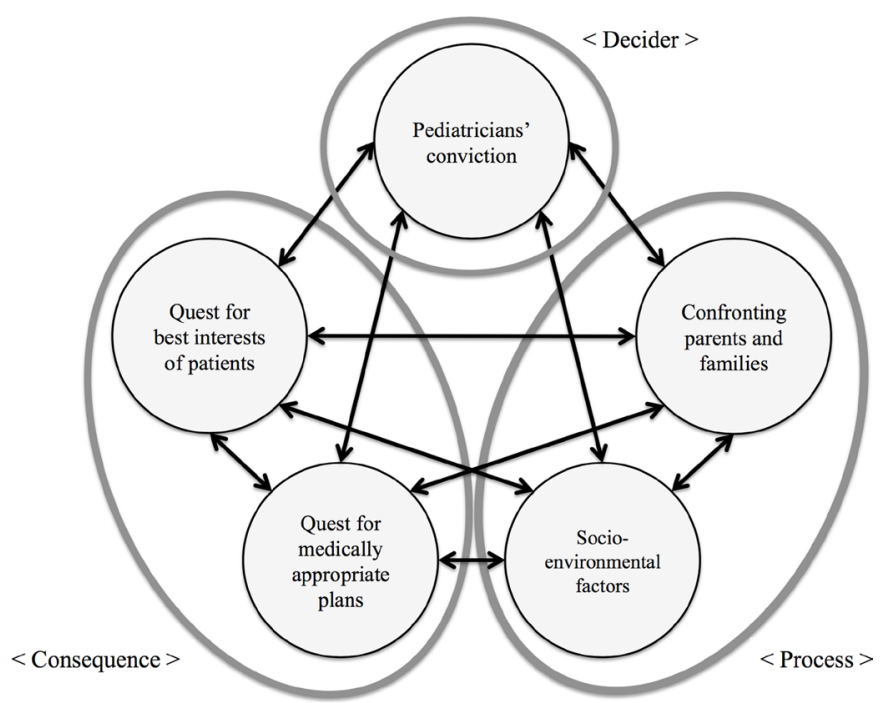

Figure 1 The five elements and three domains of paediatricians' dilemmas. The black circles indicate the five major categories (I-V) of paediatrician's dilemmas. The arrows correspond to categories $\mathrm{VI}-\mathrm{X}$ and show the conflicts among the relationships of the five major categories. Decider, process and consequence (grey ellipses) are the three domains of the five categories.

We noticed that three different standpoints were linked to these dilemmas. The condition of unfavourable conflicts among the five elements suggests, however, that dilemmas were unlikely to develop as long as the elements were well balanced. This interpretation allowed us to consider the conditions that were favourable for appropriate interplay among the five elements. Thus, we could categorise the five elements into three principal domains: the decision-maker (decider), consensus making among families, colleagues and society (process) and the consequential outputs of decisions (consequence). These three domains fit well with three major ethical theories: virtue ethics, deontology and consequentialism. ${ }^{25} 26$ Thus, it was natural that paediatricians struggled with dilemmas when seeking ethically appropriate actions in decision-making.

As noted above, we identified three subgroups in the first category of dilemmas (paediatricians' convictions). Notably, the subsumed subgroups (self-righteousness, conflicts against self-righteousness and aspiration to gain correct knowledge) were equivalent to the three fundamental dimensions for reasoning in human actions: passion, consciousness and knowledge. ${ }^{27}$ We therefore considered this to be the principal domain in coordinating the relationships among the five dilemma categories. Accordingly, solving the other elements of dilemmas had a feedback effect on paediatricians in securing their desire to make decisions that were professionally appropriate. Such a perspective supports the concept that virtue is an ethical underpinning for conducting good medical practice. ${ }^{25}$ This category also reminded us of the potential contribution of medical education: the paediatricians' convictions were linked to medical professionalism and the virtue ethics approach. In recent years, there has been a desperate need for systematic education for paediatricians. ${ }^{2829}$ One recent study showed that proper education helps physicians become tolerant professionals in terms of making correct decisions for their patients. ${ }^{30}$

We considered the remaining four 'non-convictional' categories as essential factors of dilemmas: they produced rich data content and reflected the variety of unique experiences that each paediatrician had faced. For example, when participants had conflicts when confronting parents, these data clarified how the participants responded, understood the parents' emotional burden or saw difficulty in consensus making. It would appear that the participants' empathy for patients and families could be involved in their self-confidence in the process of making appropriate decisions. ${ }^{31}$ However, what the participants expressed in words did not always belong to the category associated with their convictions, rather it defined the specificity of their dilemmas. Thus, we considered it appropriate to categorise all of the participants' experiences using verbal data and to maintain the four non-convictional elements in our schematic model.

The present study identified the unique role of paediatricians in patient-physician relationships. All 15 participants made strenuous efforts to uphold the peace in mind of parents. Participants may not have known that they should act as agents for both their patients and society $^{32}$; however, they sensitively considered whether

Table 4 Representative dilemmas harbouring the interaction between different categories

\begin{tabular}{|c|c|c|c|}
\hline Category & Subcategory & $\begin{array}{l}\text { Interview/ quote } \\
\text { no. }\end{array}$ & Quote \\
\hline $\begin{array}{l}\text { VII. Paediatricians' } \\
\text { convictions (I) versus } \\
\text { confronting parents and } \\
\text { families (IV) }\end{array}$ & $\begin{array}{l}\text { 2. Consideration for } \\
\text { parents' suffering }\end{array}$ & $8 / q 7$ & $\begin{array}{l}\text { "I began considering bronchial intubation, though } \\
\text { I was reluctant to do that. I didn't want to force the } \\
\text { child's mother to follow my opinion, and I understood } \\
\text { the mother's unspoken, desperate wish. My judgment } \\
\text { wavered momentarily." }\end{array}$ \\
\hline
\end{tabular}


the parents might accept the decisions that they made and how society might judge their efforts. It was therefore evident that the major focus of dilemmas among paediatricians might differ greatly from those of physicians in adult medicine.

Another implication of this study was the necessity of sufficient discussion in society about paediatric medicine and how we may ensure children's best interests. Towards promoting fruitful discussion in society, this study has shown what is needed to build an effective support system for paediatricians. In advance of discussion, paediatricians are expected to acknowledge their difficult experiences with dilemmas through critical decision-making. Recognising the five elements and three domains through which dilemmas are produced allows paediatricians to untangle the complex structure of decision-making. These results will return to the concept that the conviction or virtue of paediatricians influences the quality of their decision-making process and patient outcomes after the decision.

\section{LIMITATIONS OF THIS STUDY}

Several limitations associated with the present study warrant mention. First, only one researcher (MSS) conducted all 13 interviews in this study, which we consider to be both a limitation and strength of our study. By adopting this method, we were able to keep the quality of the interviews constant throughout the study; however, it might also have produced biassed results. To overcome such a weakness, we repeatedly discussed the meaning of the data, analytical procedures and interpretation among the contributors, including MSS. We further ensured the validity of interpretation by changing the contributors' roles in each interview. These extensive procedures helped minimise any potential bias in the data analysis and interpretation.

Second, the 15 participants had diverse clinical backgrounds and were recruited from different parts of Japan; however, we cannot conclude that their thoughts fully covered dilemmas faced by paediatricians today. Thus, the relative weight of the five categories remains to be determined. A nationwide quantitative study is required to address this issue.

Third, we only had one female participant. This gender bias reflects the high male-to-female ratio among paediatricians working in hospitals and providing secondary and tertiary levels of medical care. Gender has been closely linked to differential empathic skills and attitudes, ${ }^{33}$ so recruiting more female paediatricians in future studies may reveal values that were missing in the present study.

Fourth, our data underscored the value of consensus making among the participants. This may reflect their cultural background: harmony is considered to be great virtue in Japan, and this view is strongly held. ${ }^{3435}$ However, studies in Western countries have also reported common mindsets among participants. They found similar attitudes in making critical decisions to those in the present study; the authors referred to these behavioural features as a 'middle of the road' approach. ${ }^{36}$ We will address the effect of cultural and religious background factors in our future research.

\section{CONCLUSION}

This is the first qualitative study to demonstrate the decision-making framework of paediatricians and the complex structures of the dilemmas they encounter. The data show the necessity of structured education and arguments for consensus making in the field to assist paediatricians in reaching the best management plan for severely ill children.

\section{Author affiliations}

${ }^{1}$ Department of Pediatrics, Graduate School of Medical Sciences, Kyushu University, Fukuoka, Japan

${ }^{2}$ Department of Health and Welfare, Seinan Jogakuin University, Kitakyushu, Japan ${ }^{3}$ Department of Pediatric Neurology, Fukuoka Children's Hospital, Fukuoka, Japan ${ }^{4}$ Department of Nursing, Kyoto Tachibana University, Kyoto, Japan

${ }^{5}$ Department of Bio/Medical Ethics, Interdisciplinary Graduate School of Medicine and Veterinary Medicine, University of Miyazaki, Miyazaki, Japan

${ }^{6}$ President, Fukuoka Children's Hospital, Fukuoka, Japan

${ }^{7}$ Department of Child Health, Faculty of Medicine, University of Tsukuba, Tsukuba, Japan

${ }^{8}$ Department of Palliative Medicine, Graduate School of Medicine, Kobe University, Kobe, Japan

Acknowledgements We thank all of the pediatricians who participated in this study through interviews. We also thank Kazuhiko Kabe at Saitama Medical Center for helpful discussions and Dr Brian Quinn for the critical reading and extensive proofreading of the revised manuscript.

Contributors MSS conceptualised this study. MSS and YS wrote the draft, and YK supervised the manuscript. MSS, YK, YS, RK, NT, Y Ichimiya, MT and SA analysed the data. Y Ishizaki, MS, YK, MN and KI inspected the quality of data. HT, TH and SO managed the overall design of the study.

Funding This work was supported by JSPS Kakenhi grant number JP15K08555 (NT), JP15K09624 (YS), 17K16271 (Yl), 17K16301 (MT), 18K07821 (YI), a Health and Labour Sciences Research Grant on Evidence-based Early Diagnosis and Treatment Strategies for Neuroimmunological Diseases from the Ministry of Health, Labour and Welfare of Japan, Life Science Foundation of Japan, Takeda Science Foundation, The Mother and Child Health Foundation, The Japan Epilepsy Research Foundation and Kawano Masanori Memorial Public Interest Incorporated Foundation for Promotion of Pediatrics (YS). This study was conducted in agreement with the procedures in consolidated criteria for reporting qualitative research (COREQ).

Competing interests None declared.

Patient consent for publication Not required.

Ethics approval The protocol for this study was approved by the institutional review board at Kyushu University (\#26-124) on 11 August 2014.

Provenance and peer review Not commissioned; externally peer reviewed. Data availability statement Data are available upon reasonable request.

Open access This is an open access article distributed in accordance with the Creative Commons Attribution Non Commercial (CC BY-NC 4.0) license, which permits others to distribute, remix, adapt, build upon this work non-commercially, and license their derivative works on different terms, provided the original work is properly cited, appropriate credit is given, any changes made indicated, and the use is non-commercial. See: http://creativecommons.org/licenses/by-nc/4.0/.

\section{REFERENCES}

1. Hollander SA, Axelrod DM, Bernstein D, et al. Compassionate deactivation of ventricular assist devices in pediatric patients. J Heart Lung Transplant 2016;35:564-7. 
2. Kaufman SR. Ordinary medicine: extraordinary treatments, longer lives, and where to draw the line. London: Duke University Press, Durham, 2015: 191-2.

3. Hunt A, Coad J, West E, et al. The big study for life-limited children and their families. together for short lives 2013:17-29.

4. Haynes RB, Devereaux PJ, Guyatt GH. Physicians' and patients' choices in evidence based practice: Evidence does not make decisions, people do. BMJ 2002;324:1350-1.

5. Flannery L, Ramjan LM, Peters K. End-of-life decisions in the Intensive Care Unit (ICU) - Exploring the experiences of ICU nurses and doctors - a critical literature review. Aust Crit Care 2016;29:97-103.

6. Lotz JD, Jox RJ, Meurer C, et al. Medical indication regarding lifesustaining treatment for children: focus groups with clinicians. Palliat Med 2016;30:960-70.

7. McConnell T, Scott D, Porter S. Healthcare staff's experience in providing end-of-life care to children: A mixed-method review. Palliat Med 2016;30:905-19.

8. Sanderson A, Hall AM, Wolfe J. Advance care discussions: pediatric clinician preparedness and practices. J Pain Symptom Manage 2016;51:520-8

9. Frost DW, Cook DJ, Heyland DK, et al. Patient and healthcare professional factors influencing end-of-life decision-making during critical illness: a systematic review*. Crit Care Med 2011;39:1174-89.

10. Friedenberg AS, Levy MM, Ross S, et al. Barriers to end-of-life care in the intensive care unit: perceptions vary by level of training, discipline, and institution. J Palliat Med 2012;15:404-11.

11. Brown A, Clark JD. A Parent's journey: Incorporating principles of palliative care into practice for children with chronic neurologic diseases. Semin Pediatr Neurol 2015;22:159-65.

12. De Clercq E, Rost M, Pacurari N, et al. Aligning guidelines and medical practice: literature review on pediatric palliative care guidelines. Palliat Support Care 2017:1-16.

13. Makarov DV, Sedlander E, Braithwaite RS, et al. A qualitative study to understand guideline-discordant use of imaging to stage incident prostate cancer. Implementation Sci 2015;11.

14. Loeb S, Curnyn C, Fagerlin A, et al. Qualitative study on decisionmaking by prostate cancer physicians during active surveillance. BJU Int 2017;120:32-9.

15. Loeb S, Curnyn C, Fagerlin A, et al. Informational needs during active surveillance for prostate cancer: a qualitative study. Patient Educ Couns 2018;101:241-7.

16. Sadler GR, Lee H-C, Lim RS-H, et al. Recruitment of hard-to-reach population subgroups via adaptations of the Snowball sampling strategy. Nurs Health Sci 2010;12:369-74.

17. Tong A, Sainsbury P, Craig J. Consolidated criteria for reporting qualitative research (COREQ): a 32-item checklist for interviews and focus groups. Int J Qual Health Care 2007;19:349-57.
18. Barry CA, Britten N, Barber N, et al. Using reflexivity to optimize teamwork in qualitative research. Qual Health Res 1999;9:26-44.

19. Malterud K. Qualitative research: Standards, challenges, and guidelines. The Lancet 2001;358:483-8.

20. Glaser BG, Strauss AL, Strutzel E. The discovery of Grounded theory; strategies for qualitative research. Nurs Res 1968;17:364.

21. Harris T. Grounded theory. Nurs Stand 2015;29:32-9.

22. Flick $U$. Triangulation in qualitative research. A companion to qualitative research 2004;21:178-83.

23. Morita T, Miyashita M, Yamagishi A, et al. Effects of a programme of interventions on regional comprehensive palliative care for patients with cancer: a mixed-methods study. Lancet Oncol 2013;14:638-46.

24. Krippendorff K. Content analysis: an introduction to its methodology. 2nd edn. University of Pennsylvania SAGE Publication, 2004: 125-86.

25. Kotzee $B$, Ignatowicz $A$, Thomas $H$. Virtue in medical practice: an exploratory study. HEC Forum 2017;29:1-19.

26. Magelssen M, Pedersen R, Førde R. Four roles of ethical theory in clinical ethics consultation. Am J Bioeth 2016;16:26-33.

27. Kant I. Critique of pure reason. translated by Norman Kemp Smith. London: Macmillan, 1934.

28. Sahler OJZ, Frager G, Levetown M, et al. Medical education about end-of-life care in the pediatric setting: principles, challenges, and opportunities. Pediatrics 2000;105:575-84.

29. Senthil K, Serwint JR, Dawood FS. Patient end-of-life experiences for pediatric trainees spanning the educational continuum. Clin Pediatr 2016;55:811-8

30. Kesselheim JC, Najita J, Morley D, et al. Ethics knowledge of recent paediatric residency graduates: the role of residency ethics curricula. $J$ Med Ethics 2016;42:809-14.

31. Monterosso L, Ross-Adjie GM, Rogers IR, et al. How well do we understand health care professionals' perceptions and needs in the provision of palliative care? a mixed methods study. J Palliat Med 2016;19:720-7.

32. Angell M. The doctor as double agent. Kennedy Inst Ethics $J$ 1993;3:279-86.

33. Chaitoff A, Sun B, Windover A, et al. Associations between physician empathy, physician characteristics, and standardized measures of patient experience. Acad Med 2017;92:1464-71.

34. Masaki S, Ishimoto $H$, Asai A. Contemporary issues concerning informed consent in Japan based on a review of Court decisions and characteristics of Japanese culture. BMC Med Ethics 2014;15:8.

35. Tanida N. 'Bioethics' is subordinate to morality in Japan. Bioethics 1996;10:201-11.

36. Haines DKJ, Remedios L, Berney SC, et al. The conceptualisation of health-related quality of life in decision-making by intensive care physicians: a qualitative inquiry. Aust Crit Care 2017;30:152-9. 